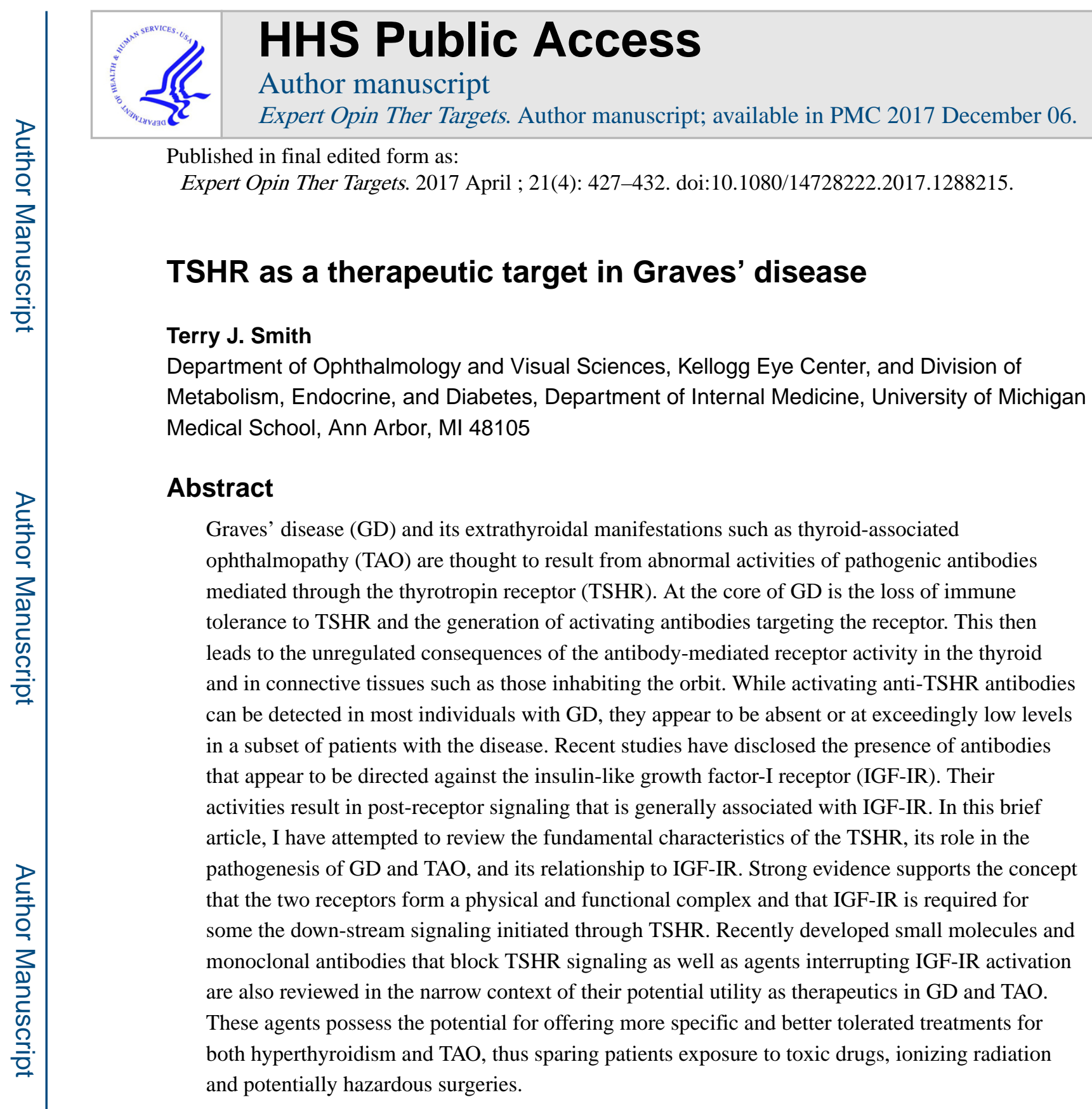

\title{
Introduction
}

Development of Graves' disease (GD) hinges on the central involvement of the thyrotropin receptor (TSHR) to which immune tolerance has been lost (1). Since the syndrome we now refer to as GD was first described in the medical literature in the early $19^{\text {th }}$ century, the curious association between enlargement and over-activity of the thyroid gland and inflammation and tissue expansion around the eyes has continued to baffle the medical community. It was not until the discovery of long-acting thyroid stimulator by Adams and Purves and the demonstration that it stimulated adenyl cyclase activity in the thyroid (2) that the relationship between TSHR and GD was first recognized. These antibodies are now

Address all correspondence and requests for reprints to Terry J. Smith, M.D., Department of Ophthalmology and Visual Sciences, Brehm Tower, 1000 Wall Street, Ann Arbor, MI 48105 Ph 734 764-0435 terrysmi@med.umich.edu. 
known as thyroid-stimulating immunoglobulins (TSI). In this brief review I have attempted to provide historical background for the evolving understanding of the physical and signaling characteristics of TSHR that may help explain its role in the pathogenesis of GD. An essential aspect of the functional role TSHR plays in health and in GD relates to the molecular partners with which it associates and which appear to provide important conduits through which TSHR channels the signals it initiates. Further, the developing concept of directly and indirectly targeting the receptor protein as a therapeutic strategy in GD is introduced as well as a proposed roadmap leading from theory to clinical application.

\section{Graves' disease}

GD is a common systemic autoimmune disease where immune tolerance to the TSHR is lost through as yet unidentified mechanisms. This misrecognition of TSHR results in the generation of TSIs that target the receptor which is densely displayed on thyroid epithelial cells $(2,3)$. The clinical hallmark of GD is abnormal growth and over-activity of the thyroid gland resulting in pathologically high levels of thyroid hormones which in turn enhance oxygen consumption and metabolism in target tissues. In addition to the effects on the thyroid, approximately $20 \%$ of patients with bona fide GD develop the ocular manifestation of the disease, known as thyroid-associated ophthalmopathy (TAO) (3). TAO represents a process of connective tissue activation and remodeling which can lead to disfigurement and blindness. In that process, TSIs acting through locally expressed TSHR in tissues peripheral to the thyroid have been implicated in the inflammation and expansion that occurs within the boney orbit $(1,4,5)$. Functional TSHR has been detected in orbital fat, extraocular muscles, and orbital fibroblasts $(6,7)$. Thus there is strong evidence to support the involvement of TSHR and the actions of TSI in both thyroid over-activity and orbital pathology in GD.

\section{Characteristics of TSHR}

The natural ligand for TSHR under ordinary states is TSH, a $27 \mathrm{kDa}$ glycoprotein hormone produced by the anterior pituitary gland that comprises two dissimilar subunits (8). It represents the dominant regulator in health of thyroid growth and thyroid hormone biogenesis. TSH associates with a determinant on the cell membrane. Amir et al first reported binding of TSH to the plasma membranes of thyroid epithelial cells in 1973 (9). Their studies disclosed a single class of sites. Further, they found that a correlation existed between TSH binding and the magnitude of cAMP generation in thyroid epithelial cells. The calculated $\mathrm{Kd}$ was $5 \times 10^{-8} \mathrm{M}$ at $\mathrm{pH}$ 7.5. Binding to bovine thyroid membranes was specific in that several related molecules, including growth hormone and prolactin, failed to alter the TSH binding characteristics. In addition TSI failed to alter the binding of $\left[{ }^{3} \mathrm{H}\right] \mathrm{TSH}$ to thyroid membranes. These early studies suggested that the binding sites for TSH and TSI on thyroid plasma membranes were dissimilar. There studies also disclosed that TSH binding to thyroid membranes could be distinguished from that demonstrated in orbital connective tissues (9).

Molecular cloning of the TSHR gene was accomplished by Parmentier and colleagues (10). They isolated a $4.9 \mathrm{~kb}$ cDNA encoding a 744 amino acid peptide. Transfection of that cDNA into Xenopus oocytes and Y1 cells resulted in cells that became responsive to TSH. TSHR 
represents the dominant molecular conduit through which thyroid epithelial cells receive externally generated, organ-specific signaling, including those that prompt growth and increase hormone biogenesis $(11,12)$. The receptor protein represents a classical 7 membrane spanning, rhodopsin-like $\mathrm{G}$ protein coupled protein. Its structure has been solved with crystallization studies by the laboratory group of Reese-Smith $(13,14)$. TSHR is a family member of cell surface receptors that includes luteinizing hormone (LH) and follicle stimulating hormone (FSH) (11). It comprises a multimeric structure $(15,16)$ with the ligand-binding site located in the amino-terminus (16). One gene encodes the receptor which is translated into a single peptide undergoing cleavage into constituent subunits connected by a disulfide bond (17). The extracellular TSHR domain is cleaved by a cell surface metalloproteinase the identity of which remains uncertain (17). This cleaved fragment is particularly immunogenic and its characteristics are likely to proximally underlie generation of TSI (15). The multimeric structure of the TSHR drives affinity maturation of the pathogenic autoantibodies in GD (15). Rearrangement of the interface between the extracellular domain-extracellular loop 1 appears to be critical to ligand-dependent receptor activation (18). TSIs mimic the actions of TSH and in so doing "fool" the TSHR into initiating signaling the epithelial cell to generate excessive amounts of thyroid hormones that in turn cause thyrotoxicosis through their exaggerated actions on target tissues (19). It would appear that the signaling patterns utilized once TSHR is activated by TSIs are similar to those resulting from the actions of TSH but these are not identical $(20,21)$. In addition to anti-TSHR antibodies that stimulate the receptor, others either block receptor activation or are neutral and assays are being developed to determine their levels in serum (22). It is important to stress that the same individual with GD can produce simultaneously both stimulatory and blocking antibodies, accounting perhaps for the rapid transition from hyperthyroidism to hypothyroidism observed in some patients. While the critical epitopes for ligand recognition and receptor activation have been identified, certain aspects of the molecular interactions between TSH and TSHR remain to be clarified.

A notable characteristic of TSHR is its behavior in the absence of bound ligand. Unligated wild-type TSHR exhibits constitutive activity (23). This ligand - independent activity results in the stimulation of G proteins and the generation of cAMP. The constitutive activity from gain of function TSHR mutations can exert significant clinical relevance, such as that occurring in the case in toxic thyroid nodules (24). Such mutations can result in hyperthyroidism and its metabolic consequences in peripheral target tissues, thyrotoxicosis (25). Among the mutations thus far identified that result in gain of function are I568 $\rightarrow \mathrm{T}$, $\mathrm{A} 623 \rightarrow \mathrm{I}$, and $\mathrm{S} 281 \rightarrow \mathrm{I}(26-29)$.

\section{Post-receptor signaling}

The signaling downstream from TSHR is complex. The receptor can interface with multiple $\mathrm{G}$ protein subtypes. Gs-induced signaling is of primary importance in the regulation of thyroid function (30). It involves several distinct pathways known to crosstalk. It is of considerable mechanistic interest that the pattern of signal pathway activation following TSI binding to TSHR diverges from that observed with TSH (21). This could potentially allow a higher degree of specificity when targeting pathological events emanating from the receptor from those driven by physiological processes. Greater detail concerning post-receptor events 
would undoubtedly allow identification of additional therapeutic targets beyond those currently identified. These include the potential roles of proteins that associate with TSHR. Among these are the $\beta$ arrestins $(31,32)$, versatile adaptor proteins that are involved in receptor internalization, desensitization, assisting receptor uncoupling from downstream targets, and facilitating receptor interactions with clathrin-coated pits. $\beta$-arrestins are capable of protein complex formation and though these aggregations are involved in the transduction of post-receptor signaling $(31,32)$. Germaine to the discussions here are the putative roles of $\beta$-arrestins in the functions of both $\mathrm{G}$ protein coupled receptors (33) and insulin-like growth factor-I receptor (IGF-IR) (34).

\section{Evidence for molecular collaboration between TSHR and IGF-IR}

IGF-I and its cognate receptor, IGF-IR, are family members of a group of molecules that play critical roles in diverse biological functions such as growth, cellular metabolism, and immunity (35). IGF-IR is a tyrosine kinase receptor that spans the plasma membrane and interfaces with several down-stream signaling pathways, leading to the regulation of a wide array of target genes $(36,37)$.

Detection of anti-IGF-IR antibodies in GD can be traced to the early work of Weightman et al (38) who demonstrated that immunoglobulins from patients with GD (GD-IgG) could displace specific binding of radiolabeled IGF-I to the surface of orbital fibroblasts. Those studies failed to identify the binding site to which the IgGs and IGF-I were competing but they were among the very first to implicate the IGF-I pathway in the disease. A decade later, Pritchard et al reported that GD-IgGs but not those from healthy controls could upregulate the expression of chemokines in orbital fibroblasts (39). Those studies demonstrated that IGF-IR was over-expressed in orbital fibroblasts from patients with GD. Further, the FRAP/Akt/mTOR/p70S6k pathway was involved in downstream signaling and the activation by GD-IgG of chemokine expression in orbital fibroblasts from these patients, including IL-16 and regulated on activation, normal T cell expressed and secreted (CCL5, RANTES) (40). The signaling provoked by GD-IgG could be attenuated by treated cultures with the specific IGF-IR antagonist, $1 \mathrm{H} 7$ and by transfecting cells with a dominant negative IGF-IR (39).

A relationship between the TSHR and IGF-IR pathways was suggested several decades ago when Ingbar and colleagues found that IGF-I could enhance certain actions of TSH while abrogating others in cultured thyroid epithelial cells (41). IGF-I was found to synergistically augment the mitogenic effects of TSH. In contrast, it could attenuate the induction by TSH of specific gene expression. Interrupting the expression of IGF-IR in thyroid results in a relative insensitivity of that gland to circulating TSH (42). On the other hand, overexpression of IGF-IR results in amplification of TSH action in vivo (43). Thus it would appear that IGF-I and its pathway appear to modify the activities of the TSH pathway. A great deal of uncertainty existed regarding the molecular basis for the interactions between the two pathways. Tsui et al reported that TSHR and IGF-IR form a physical and functional complex in thyroid tissues, orbital fat, and in fibroblasts (44). This same group detected what appears to be a fragmentation of IGF-IR into polypeptide sequences containing the alpha and beta subunits (45). Apparently, the metalloproteinase, ADAM17 is involved because a 
small molecule inhibitor of the enzyme could block receptor fragmentation. IGF-IRa can be detected translocating into the cell nucleus of fibroblasts derived from patients with GD (45). In contrast, IGF-IR $\beta$ co-localizes with TSHR and appears to mediate the signaling initiated by TSHR that culminates in downstream activation of the Erk and FRAP/ mTor/Akt/p70s6k pathways (44). The actions of TSH, TSI, IGF-I and GD-IgG can be attenuated with IGF-IR inhibiting antibodies. The dependence of TSHR-initiated signaling on IGF-IR has been confirmed recently by another laboratory group (46). This set of findings concerning the relationship between TSHR and IGF-IR and specifically the apparent transactivation by TSHR of IGF-IR has triggered exploration into whether blocking IGF-IR might result in clinical benefit to patients with TAO.

\section{Newly developed molecules for directly interrupting TSHR function}

In GD, antibodies of the IgG1 class directed against TSHR are generated as a consequence of the autoimmune reactivity underlying the disease (47). These have been characterized extensively. Their detection in the majority of patients with GD and their central role in mediating hyperthyroidism have provoked substantial interest in better understanding their interactions with TSHR protein. Coupled with their relatively recent implication in the pathogenesis of TAO, strategies for interrupting their actions make them attractive potential therapeutic targets. To this end, antibody and small molecule approaches for blocking TSI binding and activation of TSHR have been explored in recent years. Both strategies offer potentially effective means of selective therapeutic targeting the receptor in disease states with a relatively high degree of specificity when compared to the current means of medically treating hyperthyroidism. Further, these approaches might replace the need for definitive treatments and thus sparing exposure to ionizing radiation and surgery. Much has been learned from the detailed characterization of the agonistic antibodies generated against TSHR as well as those that inhibit ligand binding and thus block the actions of TSIs and TSH. Some antibodies act as inverse agonists, so designated because they inhibit the constitutive activities of TSHR (48). For instance, monoclonal antibodies that bind several regions of the receptor, including those comprising amino acids 32-41, 36-42, 246-260, 277-296, and 381-385 can block TSH binding in the ligand-binding pocket (49). On the other hand, several mouse mAbs, including B2 (50) and CS-17 (51) are effective at blocking TSH binding and TSHR activation. Human TSHR-blocking mAbs isolated from patients with autoimmune thyroid disease (52) were first reported when 5C9 was found to inhibit receptor activation by TSH and TSI and to attenuate basal receptor activity (53). Another antibody, K1-70 derives from a patient demonstrating both TSHR activating and blocking activity (54). Many of these antibodies have been characterized and have been found to possess high affinities for the TSHR (in the 100 picomolar range). Further, they can inhibit the activities of TSH and patient sera to stimulate cAMP generation. In addition to their ability to block ligand binding and thus ligand-dependent TSHR activity, some of the blocking antibodies can inhibit the activity of unligated TSHR. 5C9 appears to represent an example of that type of blocking antibody (53). This antibody blocks constitutive activity of wild-type TSHR as well as receptor harboring gain of function mutations such as those at $\mathrm{I} 568 \rightarrow \mathrm{T}$, adenosine $\mathrm{A} 623 \rightarrow \mathrm{I}, \mathrm{S} 281 \rightarrow \mathrm{I}(55)$. These insights into the structure and function 
of TSHR have allowed the initial efforts directed at targeting the protein therapeutically as a putative strategy for treating certain forms of hyperthyroidism and GD.

\section{Small molecule TSHR antagonists}

Development of small molecules as cell-surface receptor antagonists can offer specific advantages as potential therapeutics. Small molecule agonists and antagonists of TSHR have been described in the recent past, in large part coming from the laboratory of Gershingorn and his colleagues. Jaschke et al reported a small molecule a partial agonist termed Org41841, a molecule that binds to transmembrane domains of TSHR and the luteinizing hormone/chorionic gonadotropin receptor (56). This molecule was modified subsequently to yield NIIDDK/CEB-52 which exhibited inhibitory activity toward the actions of TSH and TSIs in primary cultures of human thyrocytes (57). These authors subsequently generated two additional small molecule agonists with high selectivity and potency (58). These molecules also bind to the TSHR transmembrane domain. In thyrocyte cultures, they could mimic the actions of TSH in inducing the expression of several downstream thyroid-specific genes. The molecules could be administered orally to mice and resulted in increased thyroid iodine uptake and elevated serum thyroxine concentrations (58). The inverse TSHR agonist, NCGC00161856 inhibits basal and TSH-dependent cAMP generation in HEK-EM 293 cells (59). This inhibition of TSH action was competitive. The molecule was shown to attenuate constitutive expression of TSHR, thyroperoxidase, thyroglobulin, and sodium iodide symporter in thyroid epithelial cells and has broken new ground as a small molecule reverse agonist for TSHR. A subsequent report from this lab group demonstrated that the agonist could also inhibit basal levels of cAMP, pAkt, and hyaluronan accumulation in orbital fibroblasts (60). Other studies, also in orbital fibroblasts, have revealed that the antagonist, NCGC00229600, could block the actions of the monoclonal mAb TSHR agonist, M22 and TSH (61). A subsequent report contained studies including 30 different sera, each from a different patient with GD tested in HEK-EM 293 and primary human thyrocytes (62). NCG00229600 acted as an allosteric competitor of TSH and inhibited cAMP generation provoked by all patient sera tested as well as the basal and TSI-dependent induction of thyroperoxidase. NCG00229600 attenuated the increased cAMP generation provoked by M22 and TSH in orbital fibroblasts that had been differentiated into adipocytes. ANTAG3, a TSHR antagonist exhibiting activity in vivo, was administered orally to female BALB/c mice and was found to reduce serum levels of protein unbound (free) $T_{4}$ and to dampen the expression of thyroid proteins in mice treated with thyrotropin releasing hormone (63). The effects were selective in that considerably higher doses were required to reduce the activities of luteinizing and follicular stimulating hormone receptors. Thus an array of small molecules and their derivatives have recently been developed that can act as agonists and antagonists of TSHR. With regard to the agonists, they might possess clinical utility in stimulating residual thyroid cancer. The antagonists could prove useful in treating conditions such as thyroid nodules with underlying gain of function TSHR mutations and in GD and TAO by virtue of the ability to attenuate thyroid activation provoked by stimulating antibodies.. 


\section{Blocking IGF-1R may allow therapeutic alternatives to attenuate TSHR- mediated events}

Several lines of investigation have suggested that the TSHR and IGF-IR pathways cross-talk. Moreover, it would appear that complete and robust signaling downstream from TSHR depends on uninterrupted IGF-1R function $(44,64)$. Thus strategies for blocking IGF-IR have emerged as attractive candidates for the therapy of GD by virtue of their ability to attenuate pathological signaling through both TSHR and IGF-IR pathways. That insight emerged from the studies published by Tsui and colleagues where they described that treating orbital fibroblasts from patients with TAO with the IGF-IR-blocking monoclonal antibody, $1 \mathrm{H} 7$ could attenuate activation by rhTSH and IgGs from patients with the GD of the downstream kinase, Erk (44). This was followed up several years later with confirmatory studies again demonstrating the dependence of TSHR signaling on IGF-IR (46). An example of the exploitation of these fundamental biological insights is the road to clinical translation of the fully human IGF-IR blocking antibody, teprotumumab (65) as therapy for GD and TAO. This antibody has recently been evaluated for safety and efficacy in the treatment of moderate to severe, active TAO in a phase 2 double masked, placebo controlled prospective, multicenter trial [http://clinicaltrials.gov/show/NCT01868997]. It has been shown capable of blocking the actions of IGF-I and both TSH and pathogenic TSIs in bone marrow-derived fibrocytes in vitro (64). A major barrier to therapeutically targeting the IGF-IR pathway in TAO is the potential for side effects. These can be anticipated because of the wide array of normal physiological function that this pathway is involved in regulating, including growth and metabolism. The structural similarities shared by IGF-IR and the insulin receptor make the selective modulation of each difficult but not impossible.

\section{Conclusions}

Many G protein coupled receptors have been targeted by the pharmaceutical industry as putative therapies for human disease. Rationale underlying this strategy rests from the numerous mutations detected in this family of receptors, including those identified in tumor cells (66). Should agents specifically targeting the TSHR fully mature after preclinical development and their successful navigation through informative clinical trials, their potential as therapeutics for hyperthyroidism and GD should become known. To gain registration with the United States Food and Drug Agency and/or its foreign regulatory agency equivalents, it will be necessary for these agents to demonstrate their safety when applied to a large patient population. Further, they must exhibit clear superiority over antithyroid drugs, radioiodine ablation and surgical thyroidectomy. With regard to TAO, they will need to negotiate the landscape of emerging biological agents, including those targeting the IGF-IR, the IL-6 pathway, and B lymphocytes. On the other hand, molecules such as those directly blocking the activation of IGF-IR may offer substantial benefit in treating moderate to severe, active TAO. Should these developments yield useful agents, their availability may usher in a new era in the treatment of GD and TAO. 


\section{Acknowledgments}

The expert assistance of Ms. Darla Kroft in preparing this manuscript is gratefully acknowledged. This work was supported in part by National Institutes of Health grants EY008976 and 5UM1AI110557, Center for Vision core grant EY007002 from the National Eye Institute, an unrestricted grant from Research to Prevent Blindness, and by the Bell Charitable Foundation.

\section{References}

1. Smith TJ, Hegedus L. Graves' disease. N Engl J Med. 2016; 375:1552-65. [PubMed: 27797318]

2. Adams DD, Purves HD. The role of thyrotrophin in hyperthyroidism and exophthalmos. Metabolism. 1957; 6:26-35. [PubMed: 13386966]

3. Kendall-Taylor P. Effects of long-acting thyroid stimulator (LATS) and LATS protector on human thyroid adenyl cyclase activity. Br Med J. 1973; 3:2-75. [PubMed: 4717423]

4. Smith TJ, Hegedüs L. Graves' disease. New England Journal of Medicine. 2016 in press.

5. Wang Y, Smith TJ. Current concepts in the molecular pathogenesis of thyroid-associated ophthalmopathy. Invest Ophthalmol Vis Sci. 2014; 55:1735-48. [PubMed: 24651704]

6. Feliciello A, Porcellini A, Ciullo I, et al. Expression of thyrotropin-receptor mRNA in healthy and Graves' disease retro-orbital tissue. Lancet. 1993; 342:337-8. [PubMed: 8101586]

7. Bahn RS. Thyrotropin receptor expression in orbital adipose/connective tissues from patients with thyroid-associated ophthalmopathy. Thyroid. 2002; 12:193-5. [PubMed: 11952038]

8. Szkudlinski MW, Fremont V, Ronin C, Weintraub BD. Thyroid-stimulating hormone and thyroidstimulating hormone receptor structure-function relationships. Physiol Rev. 2002; 82:473-502. [PubMed: 11917095]

9. Amir SM, Carraway TF Jr, Kohn LD, Winand RJ. The binding of thyrotropin to isolated bovine thyroid plasma membranes. J Biol Chem. 1973; 248:4092-100. [PubMed: 4122527]

10. Parmentier M, Libert F, Maenhaut C, et al. Molecular cloning of the thyrotropin receptor. Science. 1989; 246:1620-2. [PubMed: 2556796]

11. Kleinau G, Krause G. Thyrotropin and homologous glycoprotein hormone receptors: structural and functional aspects of extracellular signaling mechanisms. Endocr Rev. 2009; 30:133-51. [PubMed: 19176466]

12. Postiglione MP, Parlato R, Rodriguez-Mallon A, et al. Role of the thyroid-stimulating hormone receptor signaling in development and differentiation of the thyroid gland. Proc Natl Acad Sci USA. 2002; 99:15462-7. [PubMed: 12432093]

13. Sanders P, Young S, Sanders J, et al. Crystal structure of the TSH receptor (TSHR) bound to a blocking-type TSHR autoantibody. J Mol Endocrinol. 2011; 46:81-99. [PubMed: 21247981]

14. Sanders J, Chirgadze DY, Sanders P, et al. Crystal structure of the TSH receptor in complex with a thyroid-stimulating autoantibody. Thyroid. 2007; 17:395-410. [PubMed: 17542669]

15. Rapoport B, Aliesky HA, Chen CR, McLachlan SM. Evidence that TSH receptor A-subunit multimers, not monomers, drive antibody affinity maturation in Graves' disease. J Clin Endocrinol Metab. 2015; 100:E871-5. [PubMed: 25856215]

16. Cornelis S, Uttenweiler-Joseph S, Panneels V, et al. Purification and characterization of a soluble bioactive amino-terminal extracellular domain of the human thyrotropin receptor. Biochemistry. 2001; 40:9860-9. [PubMed: 11502179]

17. Rapoport B, McLachlan SM. TSH receptor cleavage into subunits and shedding of the A-Subunit; a molecular and clinical perspective. Endocr Rev. 2016; 37:114-34. [PubMed: 26799472]

18. Schaarschmidt J, Nagel MB, Huth S, et al. Rearrangement of the extracellular domain/extracellular loop 1 interface is critical for thyrotropin receptor activation. J Biol Chem. 2016; 291:14095-108. [PubMed: 27129207]

19. De Leo S, Lee SY, Braverman LE. Hyperthyroidism. Lancet. 2016; 388:906-18. [PubMed: 27038492]

20. Kleinau G, Neumann S, Grüters A, et al. Novel insights on thyroid-stimulating hormone receptor signal transduction. Endocr Rev. 2013; 34:691-724. [PubMed: 23645907] 
21. Morshed SA, Latif R, Davies TF. Characterization of thyrotropin receptor antibody-induced signaling cascades. Endocrinology. 2009; 150:519-29. [PubMed: 18719020]

22. Diana T, Li Y, Olivo PD, et al. Analytical performance and validation of a bioassay for thyroidblocking antibodies. Thyroid. 2016; 26:734-40. [PubMed: 26956921]

23. Huth S, Jaeschke H, Schaarschmidt J, Paschke R. Controversial constitutive TSHR activity: patients, physiology, and in vitro characterization. Horm Metab Res. 2014; 46:453-61. [PubMed: 24845969]

24. Parma J, Duprez L, Van Sande J, et al. Somatic mutations in the thyrotropin receptor gene cause hyperfunctioning thyroid adenomas. Nature. 1993; 365:649-51. [PubMed: 8413627]

25. Vassart, G., Kleinau, G. TSH receptor mutations and diseases. In: De Groot, LJ.Beck-Peccoz, P.Chrousos, G.Dungan, K.Grossman, A.Hershman, JM.Koch, C.McLachlan, R.New, M.Rebar, R.Singer, F.Vinik, A., Weickert, MO., editors. Endotext [Internet]. South Dartmouth (MA): MDText.com, Inc.; 2000-2014 Mar 30.

26. Parma J, Duprez L, Van Sande J, et al. Diversity and prevalence of somatic mutations in the thyrotropin receptor and Gs alpha genes as a cause of toxic thyroid adenomas. J Clin Endocrinol Metab. 1997; 82:2695-701. [PubMed: 9253356]

27. Kopp P, Muirhead S, Jourdain N, et al. Congenital hyperthyroidism caused by a solitary toxic adenoma harboring a novel somatic mutation (serine281-->isoleucine) in the extracellular domain of the thyrotropin receptor. J Clin Invest. 1997; 100:1634-9. [PubMed: 9294132]

28. Duprez L, Parma J, Van Sande J, et al. Germline mutations in the thyrotropin receptor gene cause non-autoimmune autosomal dominant hyperthyroidism. Nat Genet. 1994; 7:396-401. [PubMed: 7920658]

29. Alberti L, Proverbio MC, Costagliola S, et al. Germline mutations of TSH receptor gene as cause of nonautoimmune subclinical hypothyroidism. J Clin Endocrinol Metab. 2002; 87:2549-55. [PubMed: 12050212]

30. Vassart G, Dumont JE. The thyrotropin receptor and the regulation of thyrocyte function and growth. Endocr Rev. 1992; 13:596-611. [PubMed: 1425489]

31. Boutin A, Eliseeva E, Gershengorn MC, Neumann S. $\beta$-Arrestin-1 mediates thyrotropin-enhanced osteoblast differentiation. FASEB J. 2014; 28:3446-55. [PubMed: 24723693]

32. Frenzel R, Voigt C, Paschke R. The human thyrotropin receptor is predominantly internalized by beta-arrestin 2. Endocrinology. 2006; 147:3114-22. [PubMed: 16513835]

33. Luttrell LM, Lefkowitz RJ. The role of beta arrestins in the termination and transduction of Gprotein coupled receptor signals. J Cell Sci. 2002; 115:455-65. [PubMed: 11861753]

34. Povsic TJ, Kohout TA, Lefkowitz RJ. Beta-arrestin1 mediates insulin-like growth factor 1 (IGF-1) activation of phosphatidylinositol 3-kinase (PI3K) and anti-apoptosis. J Biol Chem. 2003; 278:51334-9. [PubMed: 14534298]

35. Smith TJ. Insulin-like growth factor-I regulation of immune function: a potential therapeutic target in autoimmune diseases? Pharmacol Rev. 2010; 62:199-236. [PubMed: 20392809]

36. Girnita L, Worrall C, Takahashi S, et al. Something old, something new and something borrowed: emerging paradigm of insulin-like growth factor type 1 receptor (IGF-1R) signaling regulation. Cell Mol Life Sci. 2014; 71:2403-27. [PubMed: 24276851]

37. Gallagher EJ, LeRoith D. Minireview: IGF, Insulin, and Cancer. Endocrinology. 2011; 152:254651. [PubMed: 21540285]

38. Weightman DR, Perros P, Sherif IH, Kendall-Taylor P. Autoantibodies to IGF-1 binding sites in thyroid associated ophthalmopathy. Autoimmunity. 1993; 16:251-7. [PubMed: 7517705]

39. Pritchard J, Han R, Horst N, Smith TJ. Immunoglobulin activation of T cell chemoattractant expression in fibroblasts from patients with Graves' disease is mediated through the insulin-like growth factor I receptor pathway. J Immunol. 2003; 170:6348-54. [PubMed: 12794168]

40. Pritchard J, Horst N, Cruikshank W, Smith TJ. Igs from patients with Graves' disease induce the expression of T cell chemoattractants in their fibroblasts. J Immunol. 2002; 168:942-50. [PubMed: 11777993]

41. Tramontano D, Cushing GW, Moses AC, Ingbar SH. Insulin-like growth factor-I stimulates the growth of rat thyroid cells in culture and synergizes the stimulation of DNA synthesis induced by TSH and Graves'-IgG. Endocrinology. 1986; 119:940-2. [PubMed: 2874015] 
42. Ock S, Ahn J, Lee SH, et al. IGF-1 receptor deficiency in thyrocytes impairs thyroid hormone secretion and completely inhibits TSH-stimulated goiter. FASEB J. 2013; 27:4899-908. [PubMed: 23982142]

43. Clément S, Refetoff S, Robaye B, et al. Low TSH requirement and goiter in transgenic mice overexpressing IGF-I and IGF-Ir receptor in the thyroid gland. Endocrinology. 2001; 142:5131-9. [PubMed: 11713206]

44. Tsui S, Naik V, Hoa N, et al. Evidence for an association between thyroid-stimulating hormone and insulin-like growth factor 1 receptors: a tale of two antigens implicated in Graves' disease. J Immunol. 2008; 181:4397-405. [PubMed: 18768899]

45. Hoa N, Tsui S, Afifiyan NF, et al. Nuclear targeting of IGF-1 receptor in orbital fibroblasts from Graves' disease: apparent role of ADAM17. PLoS One. 2012; 7:e34173. [PubMed: 22506015]

46. Krieger CC, Place RF, Bevilacqua C, et al. TSH/IGF-1 receptor cross talk in Graves' ophthalmopathy pathogenesis. J Clin Endocrinol Metab. 2016; 101:2340-7. [PubMed: 27043163]

47. Weetman AP, Yateman ME, Ealey PA, et al. Thyroid-stimulating antibody activity between different immunoglobulin G subclasses. J Clin Invest. 1990; 86:723-27. [PubMed: 2168443]

48. Sanders J, Miguel RN, Furmaniak J, Smith BR. TSH receptor monoclonal antibodies with agonist, antagonist, and inverse agonist activities. Methods Enzymol. 2010; 485:393-420. [PubMed: 21050929]

49. Jeffreys J, Depraetere H, Sanders J, et al. Characterization of the thyrotropin binding pocket. Thyroid. 2002; 12:1051-61. [PubMed: 12593718]

50. Sanders J, Allen F, Jeffreys J, et al. Characteristics of a monoclonal antibody to the thyrotropin receptor that acts as a powerful thyroid-stimulating autoantibody antagonist. Thyroid. 2005; 15:672-82. [PubMed: 16053383]

51. Chen CR, McLachlan SM, Rapoport B. A monoclonal antibody with thyrotropin (TSH) receptor inverse agonist and TSH antagonist activities binds to the receptor hinge region as well as to the leucine-rich domain. Endocrinology. 2009; 150:3401-8. [PubMed: 19299457]

52. Rees Smith B, Sanders J, Evans M, et al. TSH receptor - autoantibody interactions. Horm Metab Res. 2009; 41:448-55. [PubMed: 19530271]

53. Sanders J, Evans M, Betterle C, et al. A human monoclonal autoantibody to the thyrotropin receptor with thyroid-stimulating blocking activity. Thyroid. 2008; 18:735-46. [PubMed: 18631002]

54. Evans M, Sanders J, Tagami T, et al. Monoclonal autoantibodies to the TSH receptor, one with stimulating activity and one with blocking activity, obtained from the same blood sample. Clin Endocrinol (Oxf). 2010; 73:404-12. [PubMed: 20550534]

55. Furmaniak J, Sanders J, Rees Smith B. Blocking type TSH receptor antibodies. Auto Immun Highlights. 2012; 4:11-26. [PubMed: 26000138]

56. Jäschke H, Neumann S, Moore S, et al. A low molecular weight agonist signals by binding to the transmembrane domain of thyroid-stimulating hormone receptor (TSHR) and luteinizing hormone/ chorionic gonadotropin receptor (LHCGR). J Biol Chem. 2006; 281:9841-4. [PubMed: 16488885]

57. Neumann S, Kleinau G, Costanzi S, et al. A low-molecular-weight antagonist for the human thyrotropin receptor with therapeutic potential for hyperthyroidism. Endocrinology. 2008; 149:5945-50. [PubMed: 18669595]

58. Neumann S, Huang W, Titus S, et al. Small-molecule agonists for the thyrotropin receptor stimulate thyroid function in human thyrocytes and mice. Proc Natl Acad Sci USA. 2009; 106:12471-6. [PubMed: 19592511]

59. Neumann S, Huang W, Eliseeva E, et al. A small molecule inverse agonist for the human thyroidstimulating hormone receptor. Endocrinology. 2010; 151:3454-9. [PubMed: 20427476]

60. Turcu AF, Kumar S, Neumann S, et al. A small molecule antagonist inhibits thyrotropin receptor antibody-induced orbital fibroblast functions involved in the pathogenesis of Graves ophthalmopathy. J Clin Endocrinol Metab. 2013; 98:2153-9. [PubMed: 23482611]

61. Neumann S, Pope A, Geras-Raaka E, et al. A drug-like antagonist inhibits thyrotropin receptormediated stimulation of cAMP production in Graves' orbital fibroblasts. Thyroid. 2012; 22:839 43. [PubMed: 22784331] 
62. Neumann S, Eliseeva E, McCoy JG, et al. A new small-molecule antagonist inhibits Graves' disease antibody activation of the TSH receptor. J Clin Endocrinol Metab. 2011; 96:548-54. [PubMed: 21123444]

63. Neumann S, Nir EA, Eliseeva E, et al. A selective TSH receptor antagonist inhibits stimulation of thyroid function in female mice. Endocrinology. 2014; 155:310-4. [PubMed: 24169564]

64. Chen H, Mester T, Raychaudhuri N, et al. Teprotumumab, an IGF-1R blocking monoclonal antibody inhibits TSH and IGF-1 action in fibrocytes. J Clin Endocrinol Metab. 2014; 99:E163540. [PubMed: 24878056]

65. Kurzrock R, Patnaik A, Aisner J, et al. A phase I study of weekly R1507, a human monoclonal antibody insulin-like growth factor-I receptor antagonist, in patients with advanced solid tumors. Clin Cancer Res. 2010; 16:2458-65. [PubMed: 20371689]

66. O’Hayre M, Vázquez-Prado J, Kufareva I, et al. The Emerging Mutational Landscape of Gproteins and G-protein Coupled Receptors in Cancer. Nat Rev Cancer. 2013; 13:412-424. [PubMed: 23640210] 